\title{
CONFERÊNCIA REGIONAL DA UNIÃO GEOGRÁFICA INTERNACIONAL - "AMBIENTE E QUALIDADE DE VIDA NA EUROPA CENTRAL: PROBLEMAS DE TRANSIÇÃO"
}

\author{
GENTIL DUARTE(1) \\ LUÍS MORENO ${ }^{(1)}$ \\ MARGARIDA QUEIRÓS ${ }^{(1)}$ \\ JOSÉ RAFAEL SIRGADO(1) \\ MÁRIO VALE(1)
}

A Conferência Regional da União Geográfica Internacional, subordinada ao tema Ambiente e Qualidade de Vida na Europa Central: problemas de transição, realizou-se de 22 a 26 de Agosto de 1994 no Palácio da Cultura em Praga.

Os trabalhos centrais à Conferência desenvolveram-se segundo dois programas: um científico e um outro especial. O primeiro englobou plenários e sessões temáticas e envolveu todos os participantes. O segundo incluiu painéis, excursões, filmes, exposições, etc. Decorreram ainda no âmbito desta Conferência, reuniões e simpósios específicos coordenados pelas Comissões e Grupos de Estudo da UGI.

\section{1 - O PROGRAMA CIENTÍFICO}

O programa científico compreendeu sessões plenárias e sessões temáticas. As sessões plenárias reportaram-se aos seguintes assuntos:

- Transição na Europa Central: ambiente, economia e sociedade. Esta sessão valorizou as mudanças ocorridas na Europa Central nos últimos cinco anos, cobrindo os temas económicos, sociais, ambientais, regionais e geopolíticos.

- Praga: aspectos diversos. Referiram-se algumas características históricas, urbanas e culturais da Praga Milenária e Actual.

- Repúblicas Checa e Eslovaca: geografia e geógrafos. Discutiu-se a evolução e as perspectivas actuais do pensamento geográfico nestas duas Repúblicas.

(1) Investigadores do Centro de Estudos Geográficos da Universidade de Lisboa. 
- Responsabilidade Partilhada. Nesta última sessão abordou-se o papel e as relações entre as esferas política, científica e educacional.

As sessões temáticas foram agrupadas em seis secções:

- secção A - A Emergência da "Nova Europa Central";

- secção B - Ambiente e Paisagem;

- secção C - SIG, Sistemas Cartográficos e Detecção Remota;

- secção D - O Domínio da Geografia Física;

- secção E - O Domínio da Geografia Humana e Económica;

- secção F - Educação Geográfica e Ambiental.

A secção A dividiu-se nos seguintes sub-temas:

\section{A.1. O Mundo em Mudança;}

A.2. Europa Central: à procura de uma nova identidade;

A.3. Reconstrução da Europa Central: problemas e perspectivas;

A.4. Problemas da Migração e dos Refugiados.

Em A.1 analisaram-se casos de mudança e reposicionamento de determinadas regiões no mapa político mundial. Discutiu-se o diálogo Norte-Sul, a questão dos direitos humanos e a Nova Ordem Internacional, os desafios da Europa Central e Oriental e os realinhamentos geopolíticos no eixo do Pacífico.

Em A.2 consideraram-se as perspectivas de desenvolvimento de algumas regiões da Europa Central, tendo em conta os efeitos da extinção da "Cortina de Ferro" e os problemas trans-fronteiriços, incluindo a questão delicada dos territórios das minorias étnicas.

A reconstrução da Europa Central (A.3) motivou um conjunto de comunicações que se reportaram aos problemas da reconstrução económica - designadamente, a privatização de alguns sectores da economia -, aos aspectos sociais e políticos associados às mudanças recentes, à dimensão ambiental do processo de transição destas economias e aos reflexos na organização do espaço urbano.

Finalmente, em A.4, foram tratados os padrões de mobilidade e os problemas dos refugiados nas regiões da Europa Central e Oriental, alargando-se também à Chinà, Japão e ao Médio Oriente (exemplos de Israel). No encerramento desta secção foram discutidas as políticas de cidadania e as migrações internacionais. 
A secção B, dedicada ao tema genérico "Ambiente e Paisagem", segmentou-se segundo vários sub-temas, a saber:
B.1. Ambiente e Sociedade numa Perspectiva Geográfica;
B.2. Sociedade e Paisagem, Ecologia da Paisagem;
B.3. Geografia e Conservação da Natureza;
B.4. Políticas Ambientais, Planeamento e Gestão.

Em B.1 trataram-se as velhas questões das relações homem-meio, dando especial atenção às filosofias de interacção entre estes dois vectores.

Em B.2 consideraram-se as novas perspectivas para uma ecologia das paisagens e suas representações cartográficas. Buscaram-se ainda metodologias para o ordenamento da paisagem nos seus diversos usos.

Em B.3 discutiu-se a protecção dos recursos naturais em sociedades onde se manifestam conflitos de interesses entre grupos económicos, partilhando-se as experiências de gestão, protecção e conservação da natureza dos vários países de origem dos intervenientes.

As tendências actuais nas políticas de ambiente serviram de pano de fundo aos trabalhos de B.4. Novos paradigmas para um ambiente sustentado e novos rumos para a integração das necessidades sociais e económicas no ambiente foram questões amplamente discutidas. Chamou-se também a atenção para a importância dos estudos de impacte ambiental dos diversos usos do solo, e ainda para a necessidade de realização de acções de monitorização do ambiente. Concluiu-se que medir, avaliar e representar riscos são acções fundamentais no âmbito do ordenamento do território. Importante destaque foi dado às abordagens ambientais em áreas urbanas, nomeadamente no que respeita à procura da qualidade do ambiente em espaços verdes, de recreio e em áreas habitacionais e ainda nas possibilidades de valorização de certos recursos urbanos, como os resíduos. Neste âmbito, foi ainda considerada a temática das mudanças em áreas metropolitanas, ao nível da reestruturação dos sistemas produtivos, das mutações tecnológicas e das modernas formas de telecomunicação, por forma a sublinhar a questão da necessidade em investir no conceito de "cidade sustentada".

A secção C, reservada ao tema genérico "SIG, Sistemas Cartográficos e Detecção Remota", segmentou-se em:

C.1. Sistemas de Informação Geográfica em Acção;

C.2. Cartografia do Ambiente;

C.3. Detecção Remota para o Ambiente. 
Em C.1 tratou-se dos sistemas de informação geográfica, detecção remota e fotografia aérea. A produção de mapas digitais e as capacidades dos Sistemas de Informação Geográfica motivaram trocas de experiências entre os intervenientes. A geografia dos transportes, a gestão de recursos, a dinâmica das regiões de montanha, as paisagens agrícolas, o clima urbano, a localização dos espaços de recreio e o declínio das florestas, foram algumas das sugestões temáticas para úteis aplicações dos SIG. Os mapas de critérios múltiplos, a recolha das fontes de informação, o sistema de símbolos, o formato dos dados, a modelização e a visualização de funções foram de igual modo referenciados como metodologias para a criação do SIG.

A cartografia do ambiente animou C.2, em particular no que respeita aos atlas de recursos e mapas geológicos a diversas escalas.

A fotografia aérea e, cada vez mais, a detecção remota para o ambiente, foram considerados em C.3, em particular a possibilidade de combinação entre a imagem de satélite e o SIG para a melhoria das acções de medida e monitorização do ambiente: instrumento de análise ao nível da investigação, ordenamento e auditoria das paisagens.

A secção D reuniu as comunicações relativas ao tema "O Domínio da Geografia Física", destacando-se os seguintes sub-temas:
D.1. Problemas Gerais e Perspectivas da Geografia Física;
D.2. Geomorfologia Dinâmica e Engenharia;
D.3. Mudanças Climáticas e Hidrológicas;
D.4. Desastres Naturais, Acasos e Riscos.

Em D.1, as comunicações abordaram os problemas gerais e perspectivas da Geografia Física no que diz respeito aos grandes desafios que se colocam à fisiogeografia e buscaram-se respostas geomórficas às alterações naturais e antrópicas. Especial atenção foi dada à geomorfologia dinâmica e aplicada, que surgiu bastante desenvolvida em estudos de nível local. As temáticas da mudança climática e hidrológica, assim como os recursos hídricos e estudos de balanço hídrico, apareceram em trabalhos sobre sistemas climáticos globais e regionais e respectivas variações. Algumas abordagens sobre os desastres naturais, acidentes e riscos fizeram notar a utilização imprópria do termo "desastres naturais" e focaram a vulnerabilidade das grandes cidades perante estes fenómenos naturais, principalmente nos países em desenvolvimento.

Enquanto as comunicações em D.2 e D.3 se caracterizaram por destacar as análises de processos, com influência de várias ciências naturais (com peso considerável da apresentação de métodos e técnicas nos estudos de climatologia), em D.4 detiveram-se sobre as ópticas estruturalistas, acusando uma 
estreita interacção com as ciências sociais e humanas nas suas incidências mais frequentes sobre os conceitos de "bem-estar", "ambiente" e "desenvolvimento sustentado".

Na secção E, dedicada ao domínio da "Geografia Humana", trataram-se os seguintes temas:

E.1. Linhas de Força do Pensamento Geográfico;

E.2. Ambiente e Sociedade;

E.3. Reestruturação Económica;

E.4. Reestruturação Urbana, Regional e Local.

Em E.1 trataram-se fundamentalmente temas relativos ao pensamento geográfico contemporâneo, dando-se destaque às relações entre o espaço e a sociedade e entre o território e o poder.

Em E.2 apresentaram-se e debateram-se comunicações acerca da importância atribuída às percepções, valores e comportamentos humanos nas transformações ambientais do mundo actual. Trataram-se ainda questões referentes à avaliação da "qualidade de vida", relações entre ambiente e saúde, conexões entre dinâmicas políticas, culturais e étnicas na estruturação social, bem como a importância do género nas transformações sociais, com especial relevo para o papel da mulher nas sociedades contemporâneas.

A temática central em E3 incidiu sobre o processo de reestruturação económica. As preocupações com as mudanças nos padrões de desenvolvimento, ao nível da indústria e do comércio internacional, estiveram presentes. Foram apresentados muitos estudos acerca da reestruturação dos sectores de transporte e dos serviços (nomeadamente as auto-estradas, o comércio a retalho e os novos serviços bancários) e, finalmente, equacionaram-se os principais aspectos da integração dos países de Leste na economia europeia.

Analisaram-se ainda as mudanças nos padrões da economia rural e agrícola, designadamente a importância da informação na transformação destas áreas e os efeitos do mercado livre para os produtos agrícolas, e discutiu-se o conceito de "acidentes agrícolas". Foram apresentadas diversas comunicações sobre as transformações agrícolas recentes na Europa de Leste e sobre o papel dos idosos na agricultura em países desenvolvidos. Discutiram-se as condições da sustentabilidade e os contributos da reforma ambiental da P.A.C. nos espaços rurais. Como proposta para a sustentabilidade destes espaços, lançou-se a ideia das aldeias como elementos-chave (biocentros).

Os problemas do turismo e recreação foram também alvo de atenção nesta secção dedicada às actividades produtivas. As abordagens salientaram sobretudo a evolução recente do turismo e as linhas estratégicas futuras nos 
países da União Europeia. Apresentaram-se questões específicas, como a relação da SIDA com o turismo, a emergência do turismo rural e do ecoturismo, a difusão do turismo de segunda residência e o papel do turismo no desenvolvimento local.

Em E.4 debateram-se os problemas da reestruturação urbana, regional e local. Os sistemas urbanos e os processos de urbanização contemporânea foram amplamente discutidos, quer ao nível da análise teórica quer ao das abordagens empíricas. Ressaltaram-se as mudanças na estrutura interna das áreas metropolitanas e das aglomerações urbanas. A reflexão centrou-se nas bases metodológicas para a análise das áreas metropolitanas, as quais concorrem entre si na captação de investimentos e na localização de sedes de empresas internacionais. Estiveram em discussão os processos de suburbanização em diversas cidades, os seus aspectos fisionómicos e, ainda, a integração/segregação de comunidades suburbanas em território urbano.

Finalmente, foram consideradas a cooperação regional, as políticas de desenvolvimento regional e a reestruturação da administração para o desenvolvimento local.

A secção F incidiu na temática "Educação Geográfica e Ambiental":

F.1 Ambiente e Sistema de Educação e Formação Geográfica;

F.2 Tornando-se Atento;

F.3 Tornando-se Profissional;

F.4 Evolução das Preocupações Públicas;

F.5 Projectos Actuais de Investigação em Educação Geográfica e Ambiental.

Várias comunicações sobre o papel da Geografia nos sistemas de ensino, nomeadamente o seu contributo para a formação dos jovens nos curricula escolares e exemplos de experiências concretas relativas à educação geográfica, ecológica e ambiental, foram apresentadas em F.1.

O papel da relação Homem/Natureza nos livros escolares de Geografia do ensino secundário, a implementação de modelos e programas de ensino-aprendizagem, versando a temática ambiental em vários países, serviram para troca de experiências entre os presentes em F.2.

A formação geográfica no ensino superior universitário foi também alvo de diversas intervenções (F.3).

Em F.4 discutiram-se as responsabilidades partilhadas dos "media" e dos sectores público e privado na divulgação de valores ambientais e conceitos geográficos. Por fim, F.5 reuniu várias intervenções que descreveram projectos de investigação em educação Geográfica e Ambiental. 


\section{2 - O PROGRAMA ESPECIAL}

Para além do programa científico, que compreendeu as sessões plenárias e as secções temáticas, durante as quais se desenrolaram os trabalhos centrais da Conferência, o programa especial incluiu painéis de discussão, excursões, conferências de imprensa, entre outras actividades.

Esteve à disposição dos participantes uma colecção de jornais e revistas representativas dos temas centrais desta reunião, assim como vídeos e filmes.

As quatro exposições permanentes, no Palácio da Cultura, alicerçaram-se nos seguintes temas: detecção remota; SIG e cartografia para o ambiente; "media" informativos e educativos sobre o ambiente e geografia; imagens e mapas da Europa Central e acções para o ambiente.

Ao mesmo tempo que decorreram as sessões do programa científico, nas quais se debateram os conteúdos apresentados pelos participantes, reuniram as Comissões e os Grupos de Estudo da UGI, para debater as questões emergentes do seu domínio científico.

\section{3 - ALGUMAS QUESTÕES CENTRAIS DO CONGRESSO}

\section{1 - A PROBLEMÁTICA DO AMBIENTE}

Um dos principais objectivos das políticas de ambiente é o alcance de elevados padrões de qualidade de vida da população. Para tal, é necessário assegurar a compatibilidade entre o desenvolvimento económico e social e a protecção do ambiente. No futuro, o planeamento e a aplicação dos aspectos mais importantes da política ambiental serão não apenas da responsabilidade dos indivíduos mas de instituições e organizações sociais. A modificação dos modelos de crescimento caminhará no sentido de um ambiente sustentado, num contexto onde se evidencia a inter-relação da continuidade das actividades humanas e o desenvolvimento socioeconómico e da qualidade e protecção adequada dos recursos naturais.

A comunidade científica está atenta a este objectivo, pelo que a temática central a toda a Conferência foi o ambiente e a qualidade de vida. Com a abertura dos Estados-nação da Europa Central e de Leste e sua herança socialista, estas questões ganham acuidade, principalmente porque estes países centraram durante muitos anos o seu crescimento económico no processo de industrialização, na sobre-exploração das matérias-primas, na ausência de investimentos em tecnologias limpas e em produtos ecológicos. Assim se explica que o ambiente tenha sido "explorado em função da sua potencial. produtividade em vez da sua potencial habitabilidade". 
A realização de uma Conferência dedicada a este tema é a manifestação mais evidente do compromisso dos geógrafos em assumir de forma responsável e solidária a protecção do ambiente e a valorização do território.

\section{2 - AS ECONOMIAS DE TRANSIÇÃO}

Os problemas da emergente "Nova Europa Central" constituíram um dos temas centrais do Programa e foram uma excelente oportunidade de análise e de discussão sobre uma região que até muito recentemente era pouco considerada nos estudos geográficos.

Os países da Europa Central e Oriental, após a desagregação do bloco soviético, iniciaram um processo de transição de uma economia planificada para uma economia de mercado. Estas mudanças não se limitam, todavia, à esfera económica, pois têm profundas repercussões no sistema social, cultural e político.

A redução do peso do papel do Estado e a crescente participação na economia de capitais privados, de origem nacional e internacional, são dois aspectos fundamentais no desenvolvimento destes países. As perspectivas de crescimento não são, no entanto, as que se previam após o desmantelamento das sociedades socialistas. Com efeito, a formação de uma classe média com poder de consumo elevado não parece viável no horizonte mais próximo, surgindo mesmo algumas bolsas de marginalização social, com reflexos ao nível político (em alguns países verificou-se um retorno ao poder de antigos membros dos partidos socialistas). Também a reconversão das indústrias de defesa, considerada por muitos observadores como a principal actividade económica dos países de Leste, em virtude da estratégia do complexo militar soviético, tem afectado o crescimento do produto e, assim, limitado as perspectivas de uma rápida transição.

Os países da Europa de Leste, embora de uma forma desigual, são, no entanto, considerados pelos investidores externos como localizações alternativas para actividades industriais e terciárias, competindo directamente, em determinados segmentos, com a Europa do Sul. $\mathrm{O}$ apoio da UE àqueles países tem-se revelado extremamente importante (o alargamento da UE a Leste parece ser inevitável num horizonte de médio-longo prazo). Pelo nível de desenvolvimento diferenciado, os países em melhores condições para uma transição mais fácil e rápida, e posterior integração na UE, parecem ser a República Checa, a Eslováquia, a Hungria e a Polónia. 


\section{3 - DO LOCAL AO REGIONAL}

A Conferência Regional da União Geográfica Internacional reconheceu grande importância às questões de ordem local e regional. O debate, observado em torno dos mais diversos problemas, privilegia aquelas escalas de análise. Num mundo, e sobretudo na Europa, cada vez mais interdependente, todos os problemas de carácter local e regional partilham duas características essenciais. Se, por um lado, são consequência de grandes fenómenos globais (por exemplo, poluição, utilização intensiva dos recursos, sobrepopulação, desertificação, investimento internacional, crescimento urbano, nova ordem geopolítica), com impactos a uma escala mais localizada, por outro, todos os fenómenos que têm uma origem geograficamente mais circunscrita, apresentam potencialidades para poderem influenciar espaços geográficos mais vastos.

A problemática das questões locais e regionais, transversal a todas as temáticas discutidas, pode ainda ser considerada na perspectiva das orientações teóricas e metodológicas da Geografia neste fim de século. A óptica de análise local e regional continua presente no coração dos trabalhos geográficos, revelando que, para além da interdependência entre espaços, existem características concretas e particulares em cada espaço que é preciso revelar e compreender, para a construção de fundamentadas visões globalizantes.

\section{4 - O TURISMO E A RECREAÇÃO}

A problemática do turismo e recreio foi tratada especialmente na secção E.3, dedicada à reestruturação económica na Europa. Todavia, vários autores apresentaram comunicações no âmbito do turismo, lazer e recreação, inseridas noutras sessões da Conferência. Este papel transversal que o turismo mostrou tem sobretudo relação com a relevância do turismo e recreação na reestruturação económica da Europa, particularmente na Europa Central. A atenção foi sobretudo dirigida às tendências recentes e aos impactos sociais, ambientais e económicos do ecoturismo, dos turismos em áreas rurais, das segundas residências e dos turismos recreativos/activos.

A actividade turística tem actualmente um significado relevante na recomposição territorial. O processo de transição das economias, em especial na Europa Central e Oriental, traz novas oportunidades e papéis ao turismo, o que foi alvo de estudos apresentados na Conferência. Por outro lado, a componente ambiental contou com algumas abordagens interessantes sobre a fruição turística e os lazeres em espaços naturais sujeitos a regras de protecção. 